\title{
Controlled release bevacizumab in thermoresponsive hydrogel found to inhibit angiogenesis
}

\author{
Chao-Chien $\mathrm{Hu}^{\mathrm{a}, \mathrm{b}}$, Jen-Ray Chaw ${ }^{\mathrm{c}}$, Chin-Fu Chen ${ }^{\mathrm{d}}$ and Hsia-Wei Liu ${ }^{\mathrm{e}, *}$ \\ ${ }^{a}$ Department of Ophthalmology, Shin Kong Wu Ho-Su Memorial Hospital, Taipei, Taiwan \\ ${ }^{b}$ School of Medicine, Fu Jen Catholic University, New Taipei City, Taiwan \\ ${ }^{c}$ Graduate Institute of Applied Science and Engineering, Fu Jen Catholic University, New Taipei City, \\ Taiwan \\ ${ }^{d}$ Biomedical Technology and Device Research Laboratories, Industrial Technology Research Institute, \\ Hsinchu, Taiwan \\ ${ }^{e}$ Department of Life Science, Fu Jen Catholic University, New Taipei City, Taiwan
}

\begin{abstract}
Age-related macular degeneration (ARMD) and intraocular neovascular diseases have been treated clinically by anti-VEGF antibody drug bevacizumab. However, the use of bevacizumab in the treatment of retinal neovascular diseases has been limited due to the short half-life and frequent injections. In this research, novel amphiphilic hydrophilichydrophobic block copolymers of methoxy-poly (ethylene glycol)-block-poly (lactic-co-glycolic acid) were synthesized with ring-opening polymerization, and cross-linked with 2,2-bis (2-oxazoline) (BOX). The aqueous solution of the block copolymers can reverse the sol-gel-sol phase transition. After 1 month of intravitreal injection, the histomorphology of a rabbit's retina was preserved, which indicated the mPEG-PLGA-BOX hydrogel had no cytotoxicity in vivo. Released bevacizumab from the mPEG-PLGA-BOX hydrogel inhibited the RF/6A (Maraca mulatta retina epithelial cell) and HUVEC cell growth, and anti-angiogenesis in 3-D cultures, which showed the bioactivity of the anti-VEGF agent, were maintained in the hydrogel within the release process. In conclusion, the mPEG-PLGA-BOX hydrogel had a sol-gel behavior phase transition, and its intraocular biocompatibility and the characteristics of biodegradability and bioactivity appear to be a promising intravitreal injection carrier for bevacizumab delivery.
\end{abstract}

Keywords: Bevacizumab, thermo-responsive hydrogel, drug delivery system, angiogenesis

\section{Introduction}

Irreversible vision loss, even blindness, among elderly people in today's developed countries is often caused by age-related macular degeneration (ARMD). The exudative form, wet AMD, is characterized by choroidal neovascularization (CNV) [1]. Vascular endothelial growth factor (VEGF) is a key regulator of angiogenesis [2] and acts as an endothelial cell mitogen and increases vascular per-

\footnotetext{
${ }^{*}$ Corresponding author: Hsia-Wei Liu, Department of Life Science, Fu Jen Catholic University, No. 510, Jhongiheng Rd., Sinjhuang Dist., New Taipei City 24205, Taiwan. Tel.: +886-2-29053740; Fax: +886-2-29052193; E-mail: 079336@mail.fju.edu.tw.
} 
meability [3]. Since 2006, the intravitreal injection of the anti-VEGF antibody bevacizumab has shown to be effective and is widely used to treat neovascular AMD and to prevent the development of $\mathrm{CNV}$ [4]. Bevacizumab should be kept away from light and must be stocked at a temperature range of $2^{\circ} \mathrm{C}$ to $8^{\circ} \mathrm{C}$ [5]. The anti-VEGF activity of bevacizumab may degrade at a minimal level over time even when stored at $4^{\circ} \mathrm{C}$ refrigeration or in a frozen state [6]. After intravitreal injections, the antiVEGF activities of bevacizumab are most likely to degrade slowly and minimally due to the influence from body temperature and the light irradiated into the eyes. Because the half-life of bevacizumab is short (4.25 days) [7], the major concern is frequent intravitreal injections [8]. Hence, there is a great need to develop a drug carrier which can relatively slowly release the bevacizumab, protect the antiVEGF activity, and extend the half-life. Development of a drug delivery system for bevacizumab could result in a safer and more effective clinical application than the current clinical regimen for highly-prevalent neovascular retinal disorders. Biodegradable thermosensitive polymers have been used in the delivery of intravitreal injections to release bevacizumab [9], where it is captured in a thermosensitive hydrogel in a temperature higher than lower critical solution temperature (LCST) and released after the intravitreal injection. Basically, the mechanism of a biodegradable hydrogel's release is diffusion-controlled at the beginning stage and then enters a combination stage during which the diffusion and degradation co-exist (Figure 1). Biodegradable thermosensitive polymers are also a powerful matrix for a bioactive protein delivery system without an organic solvent. The main objective of this study was to demonstrate that a novel biodegradable thermoresponsive hydrogel has thermogelling properties and in vivo cytotoxicity. The study also investigated the hydrogel's ability of encapsulating and protecting the bevacizumab to extend the release duration. The released bevacizumab was not shown to lose its activation and still inhibited angiogenesis.

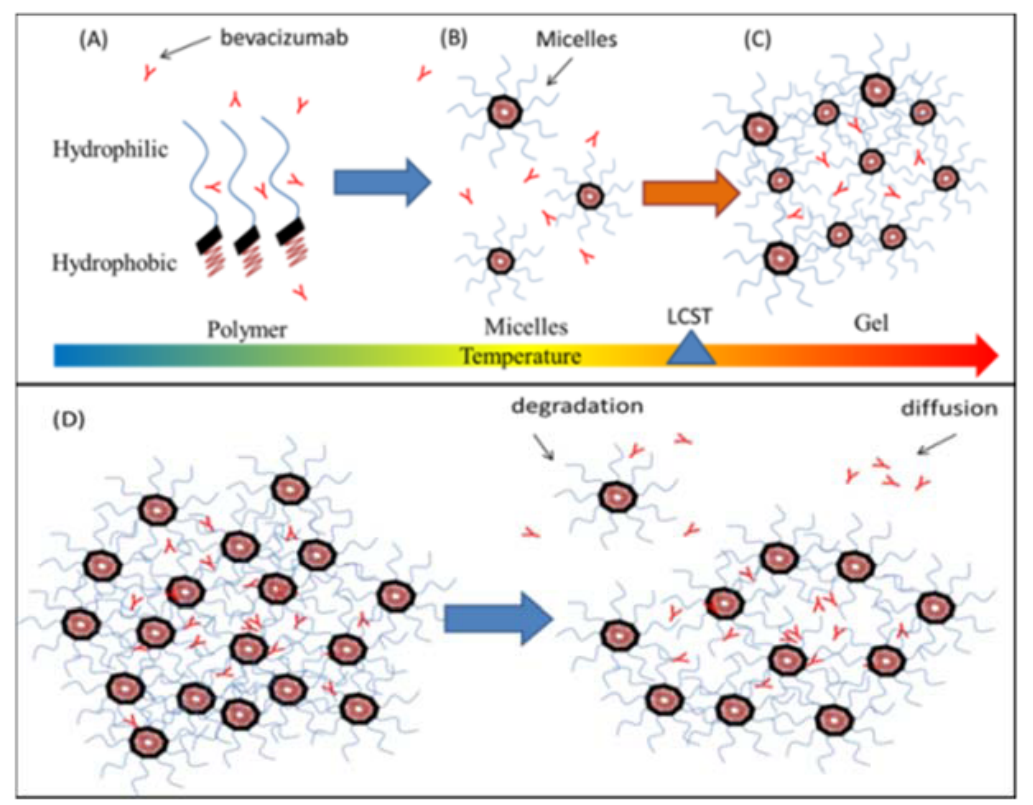

Fig. 1. Mechanism of biodegradable thermo-responsive hydrogels for drug delivery: (A) Bevacizumab is mixed with polymers at low temperature (B) Polymers self-assemble to form micelles if the concentration of polymer is higher than critical micelle concentration (CMC) (C) Bevacizumab will be entrapped in the thermosensitive hydrogel in the temperature higher than lower critical solution temperature (LCST) (D) After intravitreal injection, the bevacizumab is released by the diffusion stage and the degradation stage. 

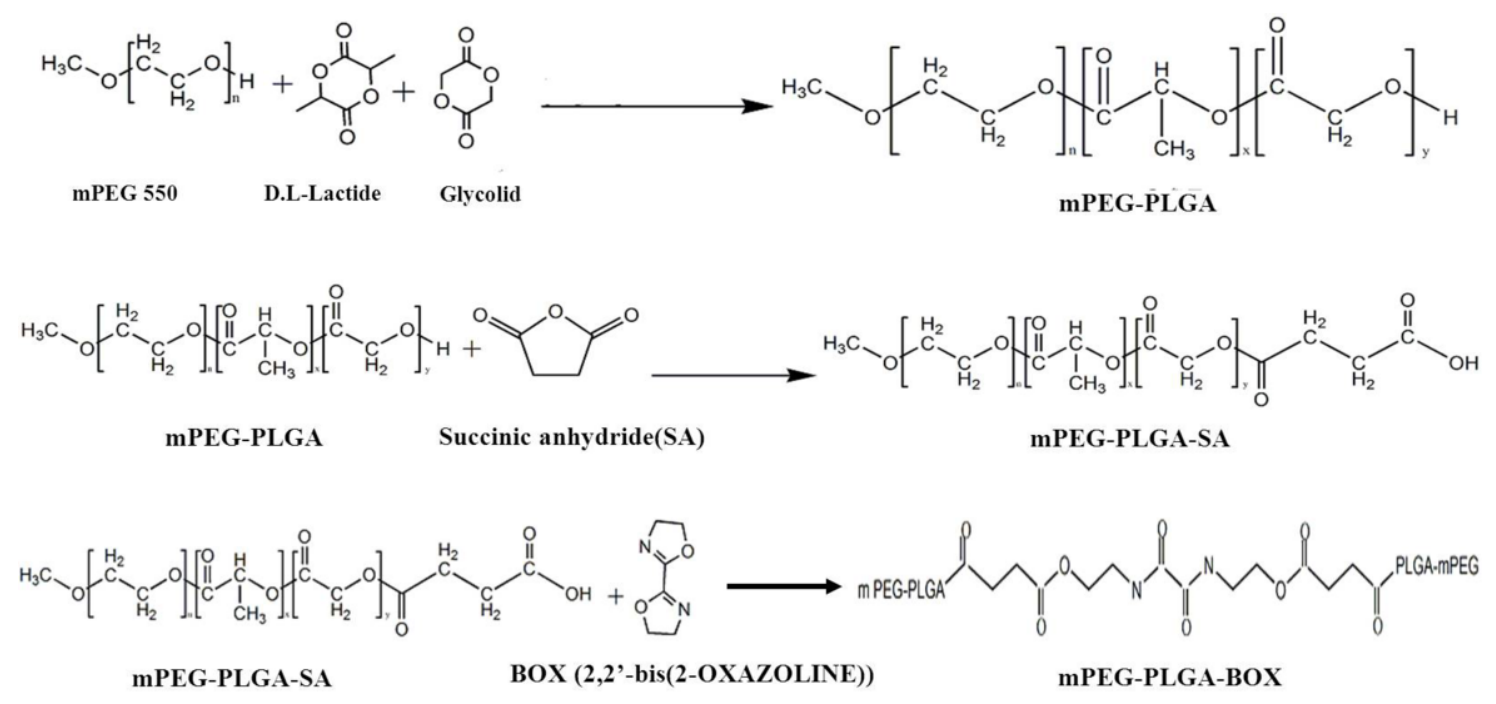

Schem. 1. Synthesis of novel thermo-responsive hydrogel for ocular drug delivery.

\section{Materials and methods}

\subsection{Preparation of $m P E G-P L G A-B O X$ diblock copolymer}

The mPEG-PLGA-BOX block copolymer was synthesized in three steps (Schem. 1). In the first step, mPEG-PLGA copolymer was synthesized. Under nitrogen at room temperature, glycolide (GA) and D,L-lactide(LA) were mixed with the mPEG solution and the addition of $0.5 \mathrm{~mL}$ of $0.1 \mathrm{M}$ solution of Tin(II) 2-ethylhexanoate or tin(II) octoate $(\mathrm{Sn}(\mathrm{Oct}) 2)$ in dried toluene The reactor temperature was kept at $160^{\circ} \mathrm{C}$ for $9 \mathrm{~h}$. The resulting copolymer mPEG-PLGA was dissolved in dimethyl sulfoxide (DMSO), and was further dialyzed to purify for 5 days at $4^{\circ} \mathrm{C}$. After dialysis, mPEG-PLGA was dried by lyophilization for 2 days. In the second step, copolymer mPEG-PLGA and DMSO (200 mL) were introduced into a three-neck reactor with a mechanical stirrer. The DMSO was then distilled to a 90 $\mathrm{mL}$ final volume. At room temperature under nitrogen, succine anhydride (SA) was mixed to the mPEG-PLGA solution. The reactor temperature was maintained at $180^{\circ} \mathrm{C}$ for $3 \mathrm{~h}$. In the third step, 2,2'-Bis (2-oxazoline) (BOX) was introduced as the linker and added into the reactor. The resulting copolymer mPEG-PLGA-BOX was further dialyzed to purify for 4 days at $4^{\circ} \mathrm{C}$. After dialysis, mPEGPLGA-BOX was dried by lyophilization for 5 days.

\subsection{Sol-gel-sol phase transition determination}

The mPEG-PLGA-BOX copolymer aqueous solutions were prepared with concentrations from 5 to $25 \mathrm{wt} \%$ (in 5\% increments). To investigate the sol-gel-sol phase transitions, the aqueous solutions were stored in glass vials at $0^{\circ} \mathrm{C}$. After overnight, the vials were put in a water bath where temperature was maintained at $0^{\circ} \mathrm{C}$ in the beginning and then slowly raised to $60^{\circ} \mathrm{C}$ (in increments of $2.5^{\circ} \mathrm{C}$ ). Each vial was kept 10 min equilibrium time under each temperature and then picked up and tilted to be observed whether the aqueous solutions glided. The phase transition temperature was recorded if the aqueous solution did not glide. 


\subsection{Cytotoxicity assay of the $m P E G-P L G A-B O X$}

A study was conducted on animal to investigate the in vivo cytotoxicity of the mPEG-PLGA-BOX hydrogel. The procedures complied with the provision of the Institutional Animal Care and Use Committees of $\mathrm{Fu}$ Jen Catholic University for the use of animals in ophthalmic and vision research. The $500 \mu \mathrm{L} 25 \mathrm{wt} \% \mathrm{mPEG}$-PLGA-BOX hydrogel was filtered with a $0.22 \mathrm{~mm}$ filter to sterilize and was then injected into the vitreous of a rabbit's right eye with a 27 -gauge needle which was inserted through the incision ( $2.5 \mathrm{~mm}$ posterior to the limbus) to $1 \mathrm{~mm}$ depth toward the optic disc. Photos of the rabbits' both eyes were taken every 7 days with a CCD in a dissecting microscope. Histological analysis was performed to confirm the in vivo cytotoxicity. On 28 days after injection, the rabbits were euthanized. Both of its eyes were removed and fixed in 10\% paraformaldehyde for 3 days. All samples were embedded in paraffin, subsequently. Sequential immersion in graded alcohol solution and xylene was used to deparaffinize and hydrate all sections. All sections were put on glass slides. All sections were stained with hematoxylin and eosin and observed by independent microscopes.

\subsection{Sustained release of bevacizumab in vitro}

On the first day, $1 \mathrm{~mL}$ bevacizumab solution $(25 \mathrm{mg} / \mathrm{mL})$ was mixed with $1 \mathrm{~mL} 50 \mathrm{wt} \%$ aqueous solution of the mPEG-PLGA-BOX (1:1 v/v ratio) to become $2 \mathrm{~mL}$ mPEG-PLGA-BOX (bevacizumab) solution whose final mPEG-PLGA-BOX concentration was $25 \mathrm{wt} \%$ and final bevacizumab concentration was $12.5 \mathrm{mg} / \mathrm{mL}$. Then, $1 \mathrm{~mL}$ bevacizumab solution $(25 \mathrm{mg} / \mathrm{mL})$ was mixed with $1 \mathrm{~mL} 40 \mathrm{wt} \%$ mPEG-PLGA-BOX (1:1 v/v ratio) to become $2 \mathrm{~mL}$ mPEG-PLGA-BOX (bevacizumab) solution whose final mPEG-PLGA-BOX concentration was $20 \mathrm{wt} \%$ and final bevacizumab concentration was $12.5 \mathrm{mg} / \mathrm{mL}$. After that, the mPEG-PLGA-BOX (bevacizumab) solution was homogenized by shaking for $5 \mathrm{~min}$ at $4{ }^{\circ} \mathrm{C}$. Next, $1 \mathrm{~mL}$ of the $25 \mathrm{wt} \%$ and $1 \mathrm{~mL}$ of the $20 \mathrm{wt} \%$ mPEG-PLGA-BOX (bevacizumab) solution were loaded into the buttons of $10 \mathrm{~mL}$ vials containing flat-bottomed tubes, the vials were incubated at $37^{\circ} \mathrm{C}$ under mild agitation in a thermostatic water bath for 5 min to form the hydrogel, and then $4 \mathrm{~mL}$ PBS was added into each vial for analyzing the bevacizumab release rate. Every day in the first 2 weeks, every 2 days in the third to sixth weeks and on Days 48, 54, and 60, the PBS media containing the bevacizumab was collected to attain the released bevacizumab from the extract of the mPEG-PLGA-BOX hydrogel. The amount of the released bevacizumab was analyzed by BIO-RAD 500-0006 KIT (Bio-Rad Labs, Richmond, CA).

\subsection{Proliferation of $R F / 6 A$ cells}

On Day 1, Macaca mulatta retina epithelial cells $(\mathrm{RF} / 6 \mathrm{~A})\left(\mathrm{ATCC}^{\circledR} \mathrm{CRL}-1780^{\mathrm{TM}}\right)$ were plated at $2 \times 10^{5}$ cells $/ \mathrm{mL}$ onto 24 -well microtiter plastic culture plates. The $\mathrm{RF} / 6 \mathrm{~A}$ was cultured at $37^{\circ} \mathrm{C}$ for 3 days. On the third day, the medium was removed and the new culture mediums, which contained different additives, were classified into 5 different mediums: (a) released bevacizumab, (b) drug-free (bevacizumab $25 \mathrm{mg} / \mathrm{mL}$ ), (c) released bevacizumab and VEGF $(10 \mathrm{ng} / \mathrm{mL}$ ), (d) drug-free (bevacizumab $25 \mathrm{mg} / \mathrm{mL}$ ) and VEGF (10 ng/mL), and (e) VEFG (10 ng/mL) (Control Group). The released bevacizumab of the $25 \mathrm{wt} \% \mathrm{mPEG}-\mathrm{PLGA}-\mathrm{BOX}$ (bevacizumab) hydrogel was taken on Days 4,9 , and 12. On the fourth day, the cell viability of the RF/6A cells was measured with a LIVE/DEAD Viability/Cytotoxicity Kit (Mode: L-3224, Molecular Probes Inc, Oregon, USA). On the sixth day, MTT assay (the 3-[4, 5-dimethylthiazol-2-yl]-2, 5-diphenyl tetrazolium bromide) was used for determination of cell viability and in vitro cytotoxicity. 


\subsection{Proliferation of HUVEC cells}

On the first, day, human umbilical vein endothelial cells (HUVECs) (ATCC ${ }^{\circledR}$ CRL1730 ${ }^{\mathrm{TM}}$ ) were plated at $8 \times 10^{3}$ cells $/ \mathrm{mL}$ onto 96 -well microtiter plastic culture plates. The HUVECs were cultured at $37^{\circ} \mathrm{C}$ for 3 days in high-glucose Dulbecco's modified eagle medium (DMEM) which contained $1 \%$ penicillin-streptomycin-amphotericin (PSA) and 10\% fetal bovine serum (FBS). On the third day, the medium was removed and the new culture mediums which contained different additives were classified into 4 different mediums: (a) released bevacizumab, (b) drug-free (bevacizumab $25 \mathrm{mg} / \mathrm{ml}$ ), (c) released bevacizumab and VEGF $(10 \mathrm{ng} / \mathrm{mL}$ ), and (d) drug-free (bevacizumab $25 \mathrm{mg} / \mathrm{mL}$ ) and VEGF $(10 \mathrm{ng} / \mathrm{mL})$. The released bevacizumab of the $25 \mathrm{wt} \%$ mPEG-PLGA-BOX (bevacizumab) hydrogel was taken on Days 4, 9, and 12. On the fourth day, the viability of the HUVECs was measured with a LIVE/DEAD Viability/Cytotoxicity Kit (Mode: L-3224, Molecular Probes Inc, Oregon, USA). On the sixth day, MTT assay (the 3-[4, 5-dimethylthiazol-2-yl]-2, 5-diphenyl tetrazolium bromide) was used for determination of cell viability and in vitro cytotoxicity.

\subsection{3-D culture and angiogenesis inhibition}

In order to investigate the angiogenesis inhibition effects of the released bevacizumab, angiogenesis assay was performed using 3-D cultured angiogenesis kit (Kurabo industries LTD, Osaka, Japan). Tube formations of capillary-like structures formed by HUVECs co-cultured with human diploid fibroblasts in Matrigel ${ }^{\mathrm{TM}}$ were photographed. HUVECs cultured with the extract of the mPEG-PLGABOX (bevacizumab) copolymer released on different days and media containing VEGF $(10 \mathrm{ng} / \mathrm{mL})$ onto 24-well plate were incubated at $37^{\circ} \mathrm{C}$ for 11 days. Media was replaced on Days $1,4,7$, and 9. $70 \%$ cold ethanol was used to fix HUVECs. Then HUVECs were incubated with mouse antihuman CD31 antibodies, then incubated with Goat anti-mouse IgG AlkP), stained with 5-Bromo-4- Chloro3\#-Indolylphosphatase p-Toluidine salt (BCIP) and nitro-blue tetrazolium chloride (NBT). And finally it was washed, and photographed to visualize the tube network at Day 11.

\section{Results and discussion}

\subsection{Sol-gel phase transition}

Figure 2 shows the sol-gel transition behaviors of the mPEG-PLGA-BOX copolymer in different temperatures. The mPEG-PLGA-BOX copolymer aqueous solutions with concentrations from 5 to 25 $\mathrm{wt} \%$ (in $5 \%$ increments) were prepared in deionized water $\left(0^{\circ} \mathrm{C}\right)$. All copolymers were dissolved in deionized water to become translucent solution at $0^{\circ} \mathrm{C}$. After overnight at $0^{\circ} \mathrm{C}$, the copolymer solutions were placed in a water bath at setting temperature, ranging from 0 to $60^{\circ} \mathrm{C}$ (in $2.5^{\circ} \mathrm{C}$ increments). From 0 to $60^{\circ} \mathrm{C}$, all the hydrogels exhibited three physical states: solution, gel, and sediment. The 5 $\mathrm{wt} \% \mathrm{mPEG}-\mathrm{PLGA}-\mathrm{BOX}$ copolymers aqueous solutions started transforming from solution to gel at $37.5^{\circ} \mathrm{C}$ and became solution phase at $45^{\circ} \mathrm{C}$. In this study, the transition temperature of sol-phase to gel phase decreased and the transition temperature of gel pahse to sol phase increased when the concentration was gradually increased from $5 \mathrm{wt} \%$ to $25 \mathrm{wt} \%$. The $10 \mathrm{wt} \%$ to $25 \mathrm{wt} \% \mathrm{mPEG}$-PLGA-BOX copolymers aqueous solutions transformed to gels at body temperature $\left(37^{\circ} \mathrm{C}\right)$. 

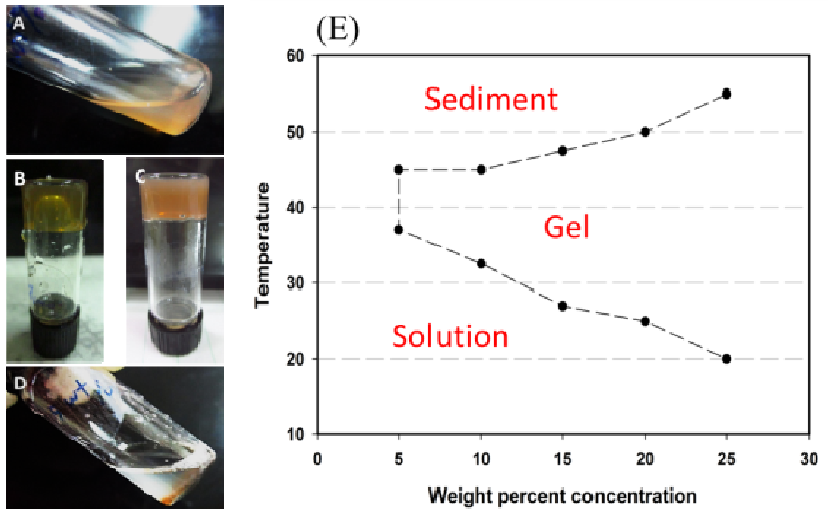

Fig. 2. (A) Solution phase (B) (C) Gel phase (D) Sediment (E) Sol-gel phase transition diagram of thermo-responsive mPEGPLGA-BOX hydrogel.

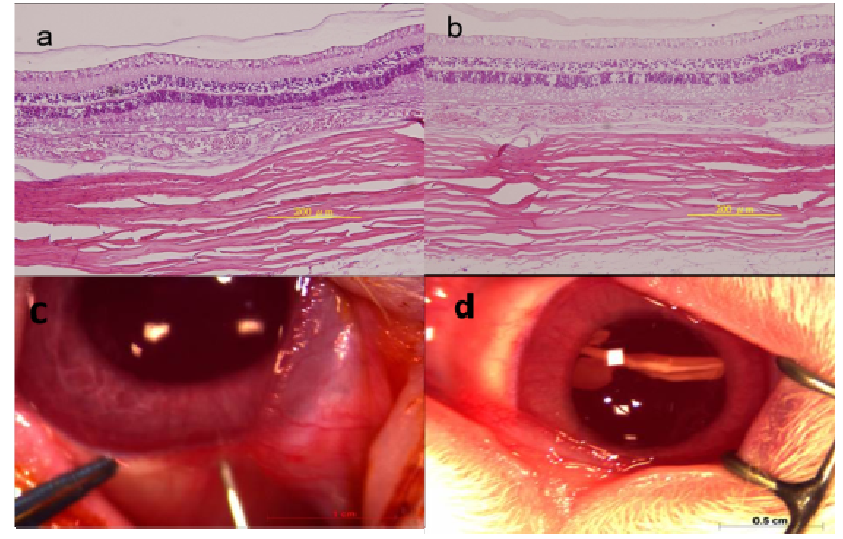

Fig. 3. Retinal section histology results for : (A) Untreated eyes; (B) $25 \mathrm{wt} \% \mathrm{mPEG}$-PLGA-BOX hydrogel solution-injected eyes (treated eyes); (C) $500 \mu \mathrm{L} 25 \mathrm{wt} \%$ mPEG-PLGA-BOX hydrogel was injected into the vitreous part in the rabbit's eye with a 27 -gauge needle which was inserted through the incision $(2.5 \mathrm{~mm}$ posterior to the limbus) to a $1 \mathrm{~mm}$ depth toward the optic disc; (D) mPEG-PLGA-BOX hydrogel in the rabbit's eyes.

\subsection{Cytotoxicity of the $m P E G-P L G A-B O X$ hydrogel}

The $25 \mathrm{wt} \% \mathrm{mPEG}-\mathrm{PLGA}-\mathrm{BOX}$ hydrogel solution $(500 \mu \mathrm{L})$ was injected into the rabbit's vitreous with a 27-gauge needle by using a dissecting microscope. One month after injection, histological analysis of the rabbit's both eyes was performed. The hematoxylin and eosin staining demonstrated a normal histology for retina tissues. For both treated and untreated eyes, no morphological changes and no infiltration of inflammatory cells were found. The outer photoreceptor and inner neuroretinal layer showed no morphological difference (Figure 3). These results proved that the mPEG-PLGA-BOX hydrogel and its degradation products are nontoxic to ocular tissue.

\subsection{Bioactivity maintenance of anti-VEGF agents in the hydrogel}

Due to the aqueous properties of the mPEG-PLGA-BOX copolymers in low temperatures, the bevacizumab could be evenly and completely encapsulated into the mPEG-PLGA-BOX copolymers. 
Although not shown in this article, the release of bevacizumab from both the $20 \mathrm{wt} \%$ and $25 \mathrm{wt} \%$ mPEG-PLGA-BOX copolymers lasted up to 30 days. There was no significant burst effect witnessed in the release profiles of these copolymers. At Day 30, the total cumulative release rate of the bevacizumab from the $20 \mathrm{wt} \%$ and $25 \mathrm{wt} \%$ copolymers was $55 \%$ and $65 \%$, respectively. After the $31^{\text {st }}$ day, the cumulative release rate did not increase over time.

The concentration of the release of the bevacizumab for the 4-day, 9-day, and 12-day extract of the $25 \mathrm{wt} \%$ hydrogel was $0.76 \mathrm{mg} / \mathrm{mL}, 0.77 \mathrm{mg} / \mathrm{mL}$, and $0.83 \mathrm{mg} / \mathrm{mL}$, respectively. Figure 4 shows the results of the MTT assay, indicating both the free bevacizumab and the released bevacizumab could inhibit the RF/6A cell and HUVEC growth, which evidenced the bioactivity of anti-VEGF agent maintenance in the hydrogel within the release process. Compared to the control group, the inhibition rate of the RF/6A cell proliferation for the released bevacizumab from the 4-day extract, free bevacizumab, released bevacizumab from the 4-day extract with VEGF, and free bevacizumab with VEGF was $45.4 \%, 44.9 \%, 44.3 \%$, and $41.9 \%$, respectively. The inhibition rate of the RF/6A cell proliferation for the released bevacizumab from the 9-day extract, free bevacizumab, released bevacizumab from the 9-day extract with VEGF, and free bevacizumab with VEGF was $43.9 \%, 42.4 \%$, $40.1 \%$, and $41.9 \%$, respectively. The inhibition rate of the $\mathrm{RF} / 6 \mathrm{~A}$ cell proliferation for the released bevacizumab from the 12-day extract, free bevacizumab, released bevacizumab from the 12-day extract with VEGF, and free bevacizumab with VEGF was $37.7 \%, 34.5 \%, 44.9 \%$, 38.3\%, respectively. Also, Table 1 shows the inhibition rate of the HUVEC cell proliferation by the released bevacizumab, free bevacizumab, released bevacizumab with VEGF, and free bevacizumab with VEGF.

Fluorescent images of the RF/6A and HUVEC cultured with the released bevacizumab and drugfree (bevacizumab $25 \mathrm{mg} / \mathrm{mL}$ ) are shown in Figures 5 and 6 . The RF/6A cells and HUVECs were stained with a LIVE/DEAD Viability/Cytotoxicity Kit. The dead cells appeared red and the live cells appeared green. For both the released bevacizumab and drug-free samples, the results showed the majority of the RF/6A cells and HUVECs were red, indicating both the released bevacizumab and drugfree samples inhibited the RF/6A cell and HUVEC growth.

Due to the fact that HUVECs are vessel endothelial cells and RF/6A cells are the closest cell type to human choroidal endothelial cells (the RF/6A cell line is from the rhesus monkey and is composed of both retinal and choroidal endothelial cells), the released bevacizumab from the mPEG-PLGA-BOX hydrogel was able to inhibit those cells, proving that the released bevacizumab did not lose its activation and was able to inhibit new blood vessel growth.

(A)

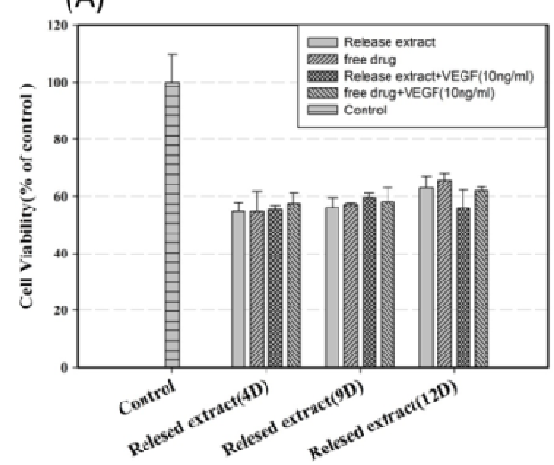

(B)

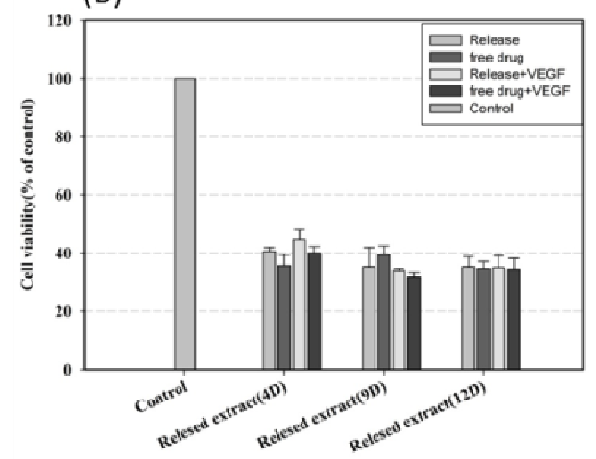

Fig. 4. MTT assay indicated: (A) RF/6A cells and (B) HUVECs were inhibited by free bevacizumab and the released bevacizumab. 
Table 1

Inhibition rate of HUVEC cell proliferation

\begin{tabular}{lllll}
\hline & Released bevacizumab & Free bevacizumab & $\begin{array}{l}\text { Released } \\
+ \text { VEGF }\end{array}$ & $\begin{array}{l}\text { bevacizumab } \\
\text { Free bevacizumab } \\
\text { +VEGF }\end{array}$ \\
\hline Release extract (4D) & $59.37 \%$ & $64.43 \%$ & $55.48 \%$ & $59.92 \%$ \\
\hline Release extract (9D) & $64.79 \%$ & $60.64 \%$ & $66.03 \%$ & $68.09 \%$ \\
\hline $\begin{array}{l}\text { Release extract } \\
(12 \mathrm{D})\end{array}$ & $64.79 \%$ & $65.32 \%$ & $65.02 \%$ & $65.54 \%$ \\
\hline
\end{tabular}

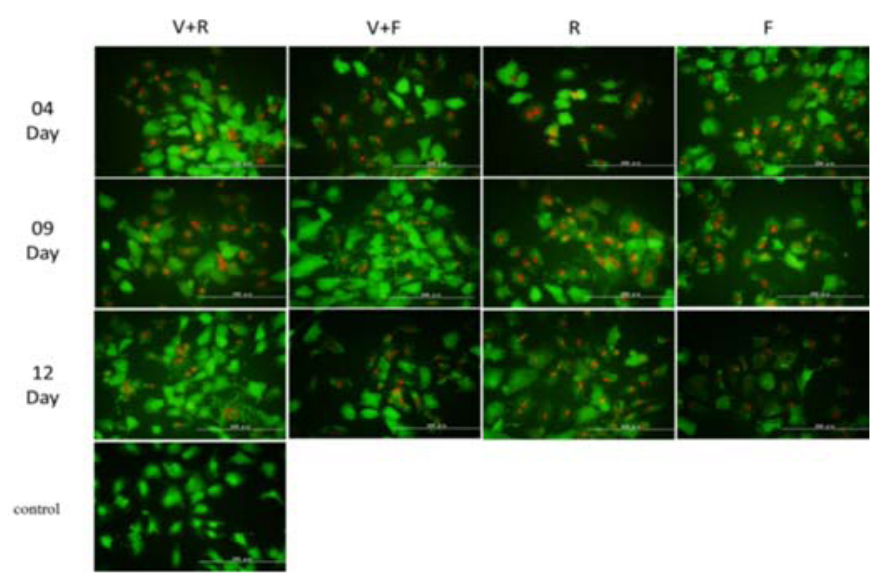

Fig. 5. RF/6A cells were cultured in medium containing released bevacizumab and VEGF $(10 \mathrm{ng} / \mathrm{mL})(\mathrm{V}+\mathrm{R})$, drug-free (bevacizumab $25 \mathrm{mg} / \mathrm{mL})+$ VEGF $(10 \mathrm{ng} / \mathrm{mL})(\mathrm{V}+\mathrm{F})$, released bevacizumab $(\mathrm{R})$, and drug-free (bevacizumab $25 \mathrm{mg} / \mathrm{mL}$ ) (F). After being stained with a LIVE/DEAD cell assay, dead cells appeared red and live cells appeared green. The extract of the $25 \mathrm{wt} \%$ mPEG-PLGA-BOX (bevacizumab) hydrogel was taken on Days 4, 9, and 12.

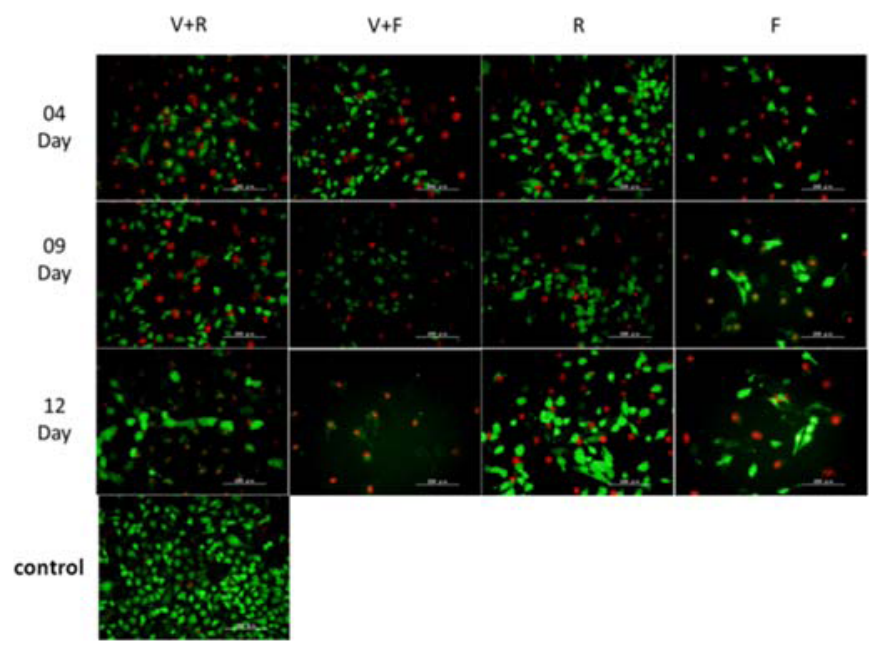

Fig. 6. HUVECs were cultured in medium containing released bevacizumab and VEGF $(10 \mathrm{ng} / \mathrm{mL})(\mathrm{V}+\mathrm{R})$, drug-free (bevacizumab $25 \mathrm{mg} / \mathrm{mL})+$ VEGF $(10 \mathrm{ng} / \mathrm{mL})(\mathrm{V}+\mathrm{F})$, released bevacizumab (R), and drug-free (bevacizumab $25 \mathrm{mg} / \mathrm{mL}$ ) (F). After being stained with a LIVE/DEAD cell assay, dead cells appeared red and live cells appeared green. The extract of the $25 \mathrm{wt} \%$ mPEG-PLGA-BOX (bevacizumab) hydrogel was taken on Days 4, 9, and 12. 


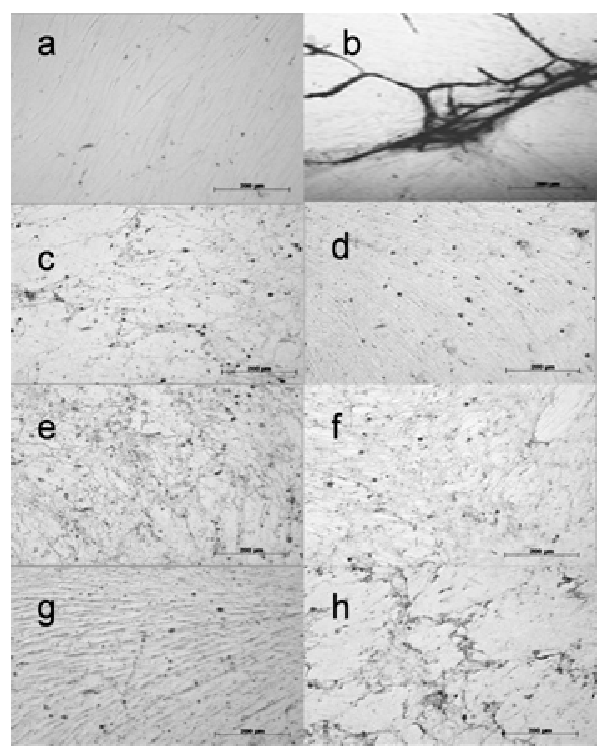

Fig. 7. Effect of released bevacizumab on the tube formation of HUVECs. HUVECs were co-cultured with fibroblasts in medium containing (A) Medium only (B) Medium + VEGF $10(\mathrm{ng} / \mathrm{mL})(\mathrm{C})$ Medium + VEGF $+0.76 \mathrm{mg} / \mathrm{mL}$ bevacizumab (D) Medium + VEGF + release bevacizumab $(0.76 \mathrm{mg} / \mathrm{mL})$ from 4-day extract of $25 \mathrm{wt} \%$ hydrogel (E) Medium + VEGF + $0.77 \mathrm{mg} / \mathrm{mL}$ bevacizumab (F) Medium + VEGF + release bevacizumab $(0.77 \mathrm{mg} / \mathrm{mL})$ from 9-day extract of $25 \mathrm{wt} \%$ hydrogel (G) Medium + VEGF + $0.83 \mathrm{mg} / \mathrm{mL}$ bevacizumab $(\mathrm{H})$ Medium + VEGF + release bevacizumab $(0.83 \mathrm{mg} / \mathrm{mL})$ from 12 -day extract of $25 \mathrm{wt} \%$ hydrogel.

\subsection{3-D culture and angiogenesis inhibition}

Since bevacizumab is an extremely potent anti-angiogenic drug, the effects of the released bevacizumab from the mPEG-PLGA-BOX hydrogel on the VEGF-stimulated tube formation of HUVECs by 3-D culture were investigated. The assay procedure was performed according to the manufacturer's instructions. The HUVECs co-cultivated with fibroblasts were cultured with $10 \mathrm{ng} / \mathrm{mL}$ VEGF and/or released bevacizumab from the extract of $25 \mathrm{wt} \%$ hydrogel for 11 days. The tube-like structure was present in the medium simultaneously added VEGF (Figure 7b). Without VEGF added to the medium, significantly the tube was not present (Figure7a). Simultaneously added different bevacizumab concentration with VEGF to medium significantly inhibited the VEGF-stimulated tube formation by HUVECs (Figures $7 \mathrm{c}, 7 \mathrm{e}$ and $7 \mathrm{~g}$ ). Meanwhile, added released bevacizumab from extract of hydrogles taken in different day also inhibited the tube formation (Figures $7 \mathrm{~d}, 7 \mathrm{f}$ and $7 \mathrm{~h}$ ). Hence, the released bevacizumab was confirmed to still possess a high anti-angiogenic effect, presumably due to inhibiting the signal transduction pathway initiated by VEGF, although it did not inhibit the HUVEC growth.

\section{Conclusion}

The mPEG-PLGA-BOX hydrogel appeared in a solution form at low temperatures, which eases its mixing with bevacizumab. At physiological temperature, it was in a gel form in which the bevacizumab could be encapsulated for controlled release. As a result, the 2, 2-bis (2-oxazoline) crosslinked mPEG-PLGA in situ forming hydrogel has the potential of being a versatile controlled-release 
carrier for intraocular drug delivery. In conclusion, the released bevacizumab from thermal-responsive mPEG-PLGA-BOX hydrogel was found to inhibit angiogenesis in vitro. Further studies are necessary to provide a complete understanding for the effects of this ocular drug delivery system on retinal and choroidal angiogenesis in vivo, even though the in vitro inhibitory effects of the released bevacizumab are indicative.

\section{Acknowledgement}

This research was financially supported by the National Science Foundation (101-2221-E-030-002) and Shin Kong Wu Ho-Su Memorial Hospital (SKH-8302-100-DR-13).

\section{References}

[1] World Health Organization, Magnitude and causes of visual impairment, Factsheet 282, November 2004.

[2] N. Ferrara and W.J. Henzel, Pituitary follicular cells secrete a novel heparin-binding growth factor specific for vascular endothelial cells, Biochem. Biophys. Res. Commun. 161 (1989), 851-858.

[3] D.W. Leung, G. Cachianes, W.J. Kuang, D.V. Goeddel and N. Ferrara, Vascular endothelial growth factor is a secreted angiogenic mitogen, Science 246 (1989), 1306-1309.

[4] Z.F. Baushur, Z.A. Haddad, A. Schakal, R.F. Jaafar, M. Saab and B. Noureddin, Intravitreal bevacizumab for treatment of neovascular age-related macular degeneration: A one-year prospective study, Am. J. ophthalmol. 145 (2008), 249256.

[5] Avastin [prescribing information], San Francisco, CA: Genentech, Inc. Data on file (SR1), December, 2004.

[6] S.J. Bakri, M.R. Snyder, J.S. Pulido, C.A. Mccannel, W.T. Weissand and R.J. Singh, Six-month stability of bevacizumab (Avastin) binding to vascular endothelial growth factor after withdrawal into a syringe and refrigeration or freezing, The Journal of Retina and Vitreous Diseases 26 (2006),519-522.

[7] S.J. Bakri, M.R. Snyder, J.M. Reid, J.S. Pulido, M.K. Ezzat and R.J. Singh, Pharmacokinetics of intravitreal bevacizumab (Avastin), Ophthalmology 114 (2007), 855-859.

[8] C.D. Regillo, D.M. Brown, P. Albraham, H. Yue, T. Ianchlve, S. Schneider, N. Shams and R. Duble-Masked, Shamcontrolled trial of ranibizumab for neovascular age-related macular degeneration: PIER study year, American Journal of Ophthalmology 145 (2008), 239-248.

[9] C.H. Wang, Y.S. Hwang, P.R. Chiang, C.R. Shen, W.H. Hong and G.H. Hsiue, Extended release of bevacizumab by thermosensitive biodegradable and biocompatible hydrogel, Biomacromolecules 13 (2012), 40-48. 